\title{
EMPREENDEDORISMO SOCIAL E ECONOMIA SOLIDÁRIA: O CASO DA COOPERATIVA DE AGENTES AUTÔNOMOS DE RECICLAGEM DE ARACAJU (CARE)
}

\author{
SOCIAL ENTREPRENEURSHIP AND SOLIDARITY BASED ECONOMY: THE CASE OF INDEPENDENT \\ AGENTS OF RECYCLING COOPERATIVE IN ARACAJU (CARE)
}

\author{
Rivanda Meira Teixeira \\ Universidade Federal de Sergipe - UFSE \\ Gregório Cerqueira Schettino \\ Universidade Federal de Sergipe - UFSE \\ Alisson Pinheiro Rodrigues \\ Universidade Federal de Sergipe - UFSE \\ José Erivaldo Mendes \\ Universidade Federal de Sergipe - UFSE
}

\section{RESUMO}

O objetivo desse estudo é analisar os principais obstáculos enfrentados pela Cooperativa de Agentes Autônomos de Reciclagem de Aracaju (CARE) para seu funcionamento. Procura-se delinear o perfil desse empreendimento e reconhecer a motivações de seu surgimento, identificar as formas de financiamento de suas atividades e por fim, apontar as dificuldades e os desafios encontrados nas suas operações. A estratégia de pesquisa adotada foi o estudo de caso único e as fontes de evidências originaram-se de fontes primárias e secundárias. Observou-se que no período inicial da formação da CARE as principais dificuldades enfrentadas foram o descrédito dos catadores no que concerne a proposta da cooperativa e a insuficiência de materiais recicláveis. Ao longo dos anos as dificuldades enfrentadas variam entre a carência de materiais para reciclagem e a falta de apoio efetivo da sociedade que não colabora com a coleta seletiva do lixo.

Palavras-chave: Empreendedorismo social. Economia solidária. Cooperativa.

\section{ABSTRACT}

The objective of this study is to analyze the main obstacles faced by the Independent Agents of Recycling Cooperative in Aracaju (CARE) for its functioning. It is looked to delineate the profile of this enterprise and to recognize the motivations of its sprouting, identify the forms of financing of its activities and point the difficulties and the challenges found in its operations. The research strategy adopted was of unique case study and the sources of evidences had originated from primary and secondary sources. It was observed that during the initial period of the formation of CARE, the main difficulties faced were the cooperate discredit with respect to cooperative aims and the insufficiency of recycle material. Throughout the years the difficulties faced vary between the lack of materials for recycling and society lack of effective support does not collaborate with the rubbish selective collection.

Keywords: Social entrepreneurship. Solidarity based economy. Cooperative. 


\section{INTRODUÇÃO}

No final do século XX houve uma disseminação das manifestações sociais organizadas pelo mundo, que Salamon (1998, p.5) chama de revolução associativa global. A crise do petróleo dos anos 70 somado ao abandono do plano assistencialista do governo nos Estados Unidos, a crise ambiental, e a crise na União Soviética, como os principais responsáveis pelo surgimento do terceiro setor nesse período.

No Brasil, Singer (2008, p. 14 - 15) destaca o período entre os anos de 81 e 86 em que a economia praticamente não cresceu e as empresas privadas se contraíram, aumentando o desemprego e a informalidade. 0 que forçou os trabalhadores a buscarem caminhos alternativos como o cooperativismo e o mutualismo, e também criou um ambiente propicio para a disseminação das ações voluntarias. Teixeira (2006) acrescenta à incapacidade do Estado em atende as variadas e numerosas necessidades da sociedade brasileira como fator que contribui para a expansão das organizações sociais no Brasil.

0 terceiro setor tem crescido no Brasil, como demonstra o Instituto Brasileiro de Geografia e Estatística (IBGE, 2006) o setor empregava cerca de 1,5 milhão de pessoas e envolvia cerca de 19,7 milhões de voluntários. O Global Entrepreneurship Monitor (GEM, 2004) apresenta que $1,05 \%$ da população adulta do Brasil estão envolvidas de alguma forma em atividades sociais ou comunitários. Segundo a Organização das Cooperativas Brasileiras (OCB, 2009) de 1990 até 2008 o numero de cooperativas cresceu 207\%. Ainda de acordo com dados divulgados pelo Ministério do Trabalho e Emprego (MTE, 2007), na década de 90, foram criados 8.554 de Empreendimentos de Economia Solidária (EES), no Brasil, enquanto que entre os anos de 2001 a 2007 foram constituídas 10.653 novas organizações, representando um aumento de aproximadamente 25\%. No Estado de Sergipe especificamente esse aumento se torna ainda mais expressivo, relativamente, onde na década de 90 foram criados 153 desses empreendimentos, e entre 2001 a 2007 surgiram 236, representando um aumento de 54\% em menos de 7 anos. (MTE, 2007).

Além do crescimento significativo do número dos empreendimentos solidários, os dados estatísticos divulgados pelo MTE (2007) também demonstram as dificuldades encontradas por essas organizações para alcançar seus principais objetivos. Os dados revelam que $21 \%$ das organizações entrevistadas não conseguiam remunerar seus sócios, e 14\% delas não tinha condições de pagar seus custos, levando-se em consideração os resultados da sua atividade econômica, sem contar as doações, quando existiam. Apenas 38\% pagaram seus custos e obtiveram excedente.

A pesquisa do MTE ainda aponta dificuldades que os empreendimentos solidários enfrentam no início do seu processo de criação. A primeira se refere ao pouco conhecimento de administração, vendas, contabilidade e marketing que os sócios possuem, e em alguns casos dificuldade de aprender técnicas administrativas devido a pouco ou nenhum grau de instrução. 0 segundo dado apontado é a desconfiança que os sócios demonstram no inicio da formação dos empreendimentos sociais.

Entretanto, segundo Falconer (1999, p.2) as pesquisas e estudos sobre esse tema não acompanham o significativo crescimento do setor no Brasil, estas ainda são tímidas. Tendo em vista a escassez de estudos científicos sobre o terceiro setor e as dificuldades que as organizações com fins sociais ainda enfrentam no seu processo de criação e desenvolvimento, se torna relevantes estudos que de alguma forma contribua para o crescimento do setor. 
O objetivo desse estudo é analisar os principais obstáculos enfrentados pela Cooperativa de Agentes Autônomos de Reciclagem de Aracaju (CARE) para seu funcionamento. Procura-se delinear o perfil desse empreendimento e reconhecer a motivações de seu surgimento, identificar as formas de financiamento de suas atividades e por fim, apontar as dificuldades e os desafios encontrados na execução de suas ações. Esse estudo pretende auxiliar futuros gestores sociais na realização de suas atividades de planejamento e desenvolvimento junto às comunidades.

\section{O TERCEIRO SETOR E A ECONOMIA SOLIDÁRIA}

O terceiro setor é "marcado" por discordâncias e indefinições quanto a sua conceituação (SALAMON, 1998, p.6). Alguns autores (GUTIERRIS, 2006, p. 42); (CALEGARE, 2005, p.36); (LANDIM, 1993); (FISCHE; FALCONER, 1998, p.12) atribuem essa indeterminação a dois fatores. Primeiro por serem classificadas diversas entidades, com características diferentes, pelo termo terceiro setor. Segundo pelo grande número de concepções existentes para definilo. Falconer (1999, p. 2) acredita que a dificuldade em conceituar é conseqüência dessa área de estudo ser muito recente. Nos Estados Unidos o tema só começou a ser estudado a partir dos anos 80 e no Brasil ainda são tímidas as pesquisas na área.

O termo terceiro setor pode ser entendido, como sugere Gutierres (2006, p. 44) como um termo que abrange o grupo de organizações que não participam do primeiro setor, o Estado, por serem empresas privadas. Nem podem pertencer ao segundo setor, o mercado, já que não visam lucro, formando assim um setor "privado, com fins públicos". Essa concepção é compartilhada por alguns autores no Brasil (FERNANDES, 1994, p. 21; FALCONER, 1999)

Entretanto há autores que discordam dessa classificação, pois agrupa organizações com características, natureza e objetivos heterogêneos (ADION, 2001) vem lembrar que nem toda organização do terceiro setor tem fins públicos, um exemplo, uma cooperativa que tem como objetivo repartir igualitariamente seus lucros entre os cooperados. Além disso, é duvidoso classificar organizações pelo que elas não são, pois não se classifica algo pelo que não é.

Para Andion (2001) é extremamente difícil tentar classificar as manifestações da sociedade civil na área social devido à sua grande variedade e especificidade, dessa forma um único termo englobar para todas as organizações sociais, que são frutos dessas manifestações, se torna incompleto. 0 referido autor sugere classificar as organizações com fins sociais em três grupos. 0 primeiro grupo é o da economia social, mais próximo da esfera do mercado, formado por cooperativas e mutuais de créditos. 0 segundo grupo é o do terceiro setor formado pelas fundações e institutos públicos e privados e pelas organizações nãogovernamentais (ONGs) que não atuam diretamente na comunidade,. Por último as economias solidárias que para a autora é formado por ONGs de atuação direta nas comunidades, grupos comunitários e voluntariados, além das organizações filantrópicas.

Apesar de toda indefinição quanto ao termo terceiro setor, as atividades voluntariadas organizadas, as organizações privadas sem fins lucrativos ou não governamentais, que são em geral classificadas por esse termo, só vêem aumentado principalmente no final dos anos 80, na America Latina, Ásia e nos países que pertenceram ao antigo bloco soviético. (SALAMON, 1998, p.5). 0 que mostra que a ausência de conceituação não chega a ser um impedimento para as organizações sociais se expandirem (FISCHE; FALCONER, 1998, p.13). 
Para Salamon (1998, p.7) o crescimento do terceiro setor é explicado por forças de pressão que agem como catalisadores no setor voluntariado, que tem três origens. A primeira fonte de origem é chamada pelo autor de origem De baixo que se caracteriza pelas motivações que surgem espontaneamente nas comunidades. A segunda origem chamada de origem De cima, quando o governo de países ou da localidade apóia e incentiva essas ações na sociedade civil através de políticas públicas. E de fora, quando organizações públicas ou privadas externas a comunidade atuam, sendo repassando capital e/ou indo até as comunidades ajudar a organizá-las, como por exemplo, a igreja Católica na America Latina e as ONGs internacionais.

Os acontecimentos que explicam a aparecimento do terceiro setor atualmente são originados, segundo Salamon (1998, p.8) por quatro crises e duas mudanças revolucionarias. 1) Crise do welfare state, quando nos Estados Unidos as ações assistencialistas do governos não funcionam mais, principalmente com o aparecimento da crise do petróleo dos anos 70. 2) A pobreza gerada pela crise do Petróleo dos anos 70. 3) Crise ambiental. 4) 0 fim o bloco Soviético. As mudanças apontadas por Salamon $(1998$, p.8) seriam o aumento de índices de alfabetização e educação e a revolução da comunicação, permitindo assim, acesso das populações mais pobres a informação.

Um seguimento que cresceu dentre as organizações do terceiro setor são empreendimentos de economia solidária, 2001 a 2007 houve um crescimento de $25 \%$ no Brasil em relação à década de 90 (MTE, 2004). A economia solidaria aparece com destaque no Brasil depois da crise do período compreendido entre os anos de 81 a 86, como uma forma alternativa que alguns trabalhadores encontraram para fugir do desemprego gerado pela crise, e conseqüentemente de um processo de exclusão (SINGER, 2008a, p.14-15).

A economia solidária é formada por duas características que se destacam. Primeiramente pela igualdade de direitos, onde todos que compõem o quadro de trabalhadores são donos dos meios de produção. Segundo pela autogestão, ou seja, o processo de tomada de decisões dos empreendimentos de economia solidária é realizado democraticamente por todos os seus trabalhadores. A primeira característica se destaca ainda mais do que a segunda, pois quem trabalha é também o proprietário dos meios de produção, situação inversa da do capitalismo que sempre se caracterizou pela separação de quem trabalha e de quem possui os meios de produção. (SINGER, 2008b).

Segundo Medeiro e Macedo (2007), as cooperativas auto-geridas podem ser a melhor forma para a inclusão de talhadores sem empregos, como o caso dos catadores de lixo que são trabalhadores excluídos, pois trabalham e prestam serviços para as empresas de reciclagem, catando e separando o material reciclável do lixo, onde estas decidem o preço do produto dos catadores, além de não garantirem nenhum direito trabalhista a esses catadores.

Dessa forma as autoras vêem a união dos catadores em cooperativas como a chance deles formalizarem seu trabalho, tendo acesso assim a seus direitos, como por exemplo, à aposentadoria.

\section{EMPREEDEDORISMO SOCIAL}

O empreendedorismo social, que surge devido à dificuldade do Estado em atender todas as numerosas e variadas demandas da sociedade. Especialmente em países como o Brasil, devido à amplitude e intensidade das carências sociais (TEIXEIRA, 2006), não é um fenômeno novo, e suas origens datam dos séculos XVIII e XIX, com a atuação de empresários filantropos (SHAW; CARTER, 2007 apud LEZANA, GARCIA, FARES, GRAPEGGIA e GARGIONI, 2008, p. 2) e 
movimentos religiosos. Porém, somente nos últimos anos foram realizados estudos que foquem este assunto. Por esta razão, ainda não há, segundo Peredo e MacLean (2006, apud LEZANA, GARCIA, FARES, GRAPEGGIA e GARGIONI, 2008, p. 2), um consenso sobre a definição de "empreendedorismo social", "empreendimento social" ou "empreendedor social" expressões que, embora tenham focos um pouco diferentes, são, aqui, abordadas conjuntamente, por serem faces do mesmo fenômeno.

De acordo com Mattos et al (2008, p. 3), o empreendedorismo social se apresenta como uma alternativa emergente de desenvolvimento humano local e de emancipação social frente a diversas ações de combate à pobreza e à exclusão, algumas das expressões mais nítidas das múltiplas dimensões da questão social. Já os autores Melo Neto e Froes (2002) apresentam o empreendedorismo social como um paradigma emergente de um novo modelo de desenvolvimento: um desenvolvimento humano, social e sustentável. Para os autores, mudase o foco do negócio, que tem nas empresas, sobretudo nas grandes transnacionais e nas grandes instituições financeiras, o seu principal eixo de atuação, para o negócio do social, que tem na sociedade civil o seu principal foco, e na parceria envolvendo comunidade, governo e setor privado. Para os autores citados, a comunidade auto-sustentável será viabilizada através do fomento de ações empreendedoras de cunho social e de novas estratégias de inserção social e de sustentabilidade (MELO NETO e FROES, 2002, p. 41).

É importante frisar que desenvolvimento social significa desenvolvimento não desigual, isto é, desenvolvimento com redução de desigualdades, com inclusão social. E isto supõe a articulação de diversos fatores econômicos e extra-econômicos, como conhecimento e poder, além de renda e riqueza. A dinamização do desenvolvimento econômico, quando desvinculada de processos de conhecimento e poder, resulta, quase sempre, em concentração de renda e riqueza, combinada com exclusão social (DE PAULA, 2001).

Segundo Fontes (2000), as organizações do terceiro setor se caracterizam como organizações que compõem redes sociais, alimentadas pela solidariedade, cooperação e interação de diversos atores sociais (Estado, empresas e organismos sociais). Neste sentido, o autor destaca que estas organizações são produtoras, por excelência, de ações que geram capital social, ou seja, propiciam ações conjuntas em prol do enfrentamento dos problemas sociais, de forma a valorizar relações, cooperação, interação e fortalecimento dos laços de solidariedade, fazendo com que surjam novas formas de entender e enfrentar os problemas sociais existentes.

Dentro dessas perspectivas apresentadas, o empreendedorismo social funciona como um agente da criatividade comunitária e é compreendido como aquele que, mediante sua criatividade, toma para si a tarefa de solucionar problemas e buscar benefícios para a sua comunidade. Configura-se, dessa maneira, a tarefa do empreendedor social dentro de uma visão focada na criatividade, pois ele realiza uma ação inovadora aplicada ao social (instituições, bairros, comunidades) como processo criativo.

No entanto, muitos são os problemas no cotidiano dos empreendimentos sociais, tais como: carência de capital de giro, acesso ao crédito, tecnologia, problemas decorrentes das barreiras legais, carência de apoio, conflitos entre outros. E a temática do empreendedorismo social requer uma ação coordenada de todas as pessoas envolvidas, exigindo que as relações entre a comunidade, governo e setor privado sejam bem estruturadas, buscando soluções para as problemáticas enfrentadas no curto, médio e longo prazo a fim de se promover inclusão social e desenvolvimento local. 
É nesse sentido que se demonstra a importância do empreendedor social, que segundo Ashoka (2001, p. 35), é "alguém que tem idéias novas, pensa e age criativamente, tem personalidade empreendedora e coloca em tudo que pensa e faz o ideal de produzir impacto social benéfico", e é "movido a idéias transformadoras e assume uma atitude de inconformismo e crítica diante das injustiças sociais existentes em sua região e no mundo" (MELO NETO e FROES, 2002, p. 34). Portanto, cabe ao empreendedor social cumprir o desejo de ajudar as pessoas, gerando coletividade e inclusão social, vindo a implementar ações que promovam a melhoria e o bem estar social.

\section{METODOLOGIA}

Este trabalho tem a finalidade de analisar os obstáculos encontrados pela Cooperativa de Agentes Autônomos de Reciclagem de Aracaju (CARE), uma cooperativa de catadores de lixo situada na cidade de Aracaju. Trata-se de uma pesquisa qualitativa, de caráter exploratório, que de acordo com Gil (2002), tem como intuito principal poder proporcionar uma maior compreensão do fenômeno do qual se está investigando.

A estratégia de pesquisa adotada foi o estudo de caso único que, segundo Yin (2001), seria a forma mais adequada para compreender questões do tipo "como" e "por que" certos fenômenos ocorrem, quando se há pouco controle sobre os eventos estudados e quando o foco de interesse é sobre fenômenos atuais, que só poderão ser analisados sobre um contexto de vida atual.

As fontes de evidencias originaram-se de fontes primárias e secundárias. Os dados foram levantados através de entrevista baseada em roteiro semi-estruturado. A entrevista foi realizada com uma cooperada que está na CARE desde sua fundação em 1999 e que atualmente ocupa a função de tesoureira da instituição. As questões levantadas na entrevista buscaram compreender o perfil dos participantes da CARE, suas principais dificuldades, parcerias, formas de financiamento, principais clientes e a descrição de suas atividades.

A escolha da CARE como objeto de estudo se deve por ser um empreendimento de economia solidaria de sucesso reconhecido no Estado de Sergipe. Seu surgimento proporcionou uma alternativa a algumas famílias do bairro Santa Maria, submetidas ao trabalho insalubre, informal e marginalizado dos lixões. Além é claro do aumento de renda dessas famílias. Outra razão para a sua escolha diz respeito à acessibilidade por parte dos seus organizadores, que entendem como importante a pesquisa sobre sua forma de trabalho, e têm interesse que sua experiência de sucesso se estenda a outras comunidades carentes.

\section{O ESTUDO DE CASO: A CARE}

A CARE é uma cooperativa de catadores de lixo, localizada no Bairro Santa Maria, zona sul de Aracaju, que teve a sua formação iniciada no ano de 1999, porém só em 19 de julho de 2001 foi efetivamente inaugurada. 0 seu processo de criação teve inicio com a ação conjunta do Ministério Público, UNICEF, UFS e EMSURB, na busca do combate ao alto índice de trabalho infantil na cidade, porém, mesmo com a inserção das crianças no Programa de Erradicação do Trabalho Infantil (PETI) e na Escola, a problemática persistia, visto que as crianças da comunidade continuavam a trabalhar no lixão após o período das aulas, para auxiliar seus pais para melhoria da renda familiar. Essa situação é descrita pela tesoureira no fragmento da entrevista a seguir:

A CARE foi, mais ou menos motivada, pela UNICEF junto com o Ministério Público, a EMSURB e UFS. Foram até o lixão, porque aqui em Aracaju o maior 
foco, na época que foi em 1999, o maior foco era o lixão, com 240 crianças que moravam lá, junto com as famílias, e aí para ajudar na renda da família, com quatro e cinco anos iam trabalhar. Daí o Ministério Público foi registrou alguns, colocou as crianças na escola, só que os meninos iam para a escola 07:00 horas da manhã e retornavam às 17:00 horas, só que quando dava 22:00 horas da noite, desciam para o lixão para irem trabalhar, então não adiantava nada, porque 04 horas eles iam dormir, 07:00 horas teriam que estar dentro do ônibus, aí começavam a dormir dentro da sala e tal.

Diante dessa circunstância, o Ministério Público começou a investigar junto às famílias da comunidade Santa Maria, as estratégias de combate ao trabalho infantil e a garantia das crianças na escola e, conseqüentemente distantes do trabalho degradante da lixeira. Do resultado dessa consulta surgiu a proposta da criação de uma cooperativa de materiais recicláveis, tendo em vista que muitas famílias sobreviviam da renda adquirida no trabalho de coleta do lixo, pois nesta região existe a lixeira central de toda a cidade de Aracaju.

O objetivo da cooperativa seria a garantia de renda às famílias cooperadas, afastar as crianças do trabalho, mantê-las na escola num turno e no outro em programas e projetos sociais, e contribuir para a melhoria da qualidade de vida de toda a comunidade. Inicialmente, a idéia não foi recebida com muita credibilidade pelos catadores devido a experiências anteriores que não se concretizaram. A falta de confiança dos cooperados na formação de um empreendimento social, como aconteceu na CARE, aparece em outros estudos como em HOCAYEN-DA-SILVA et al (2009) onde 31\% dos empreendimentos pesquisados apontaram essa dificuldade. Por isso a cooperativa teve inicio com apenas 06 cooperados, que foi aumentando gradativamente e hoje conta com a participação de 45 famílias. Como mostra o depoimento da entrevistada:

Como nós já tínhamos ouvido falar várias vezes essa mesma proposta e só dava em nada, fiquemos meio assim, mas disseram: vamos tentar. E graças a Deus estamos aqui.

No que diz respeito ao perfil das famílias, antes da cooperativa funcionar, constata-se que estavam afastados do mercado de trabalho, em situação de extrema vulnerabilidade social, e sustentavam-se com a renda obtida com a coleta do lixo. Com a cooperativa, as condições de trabalho tornaram-se mais dignas, pois a coleta, armazenamento, separação e venda dos resíduos sólidos passaram a ser realizados em um espaço físico adequado, o emprego tornouse formal e a renda é suficiente para o sustento das famílias cooperadas ao ponto das crianças não precisarem trabalhar, como explica a entrevistada:

É porque a renda, nós tirávamos do trabalho da gente dentro do lixão, do mesmo jeito que a gente tira aqui, só que agora com mais dignidade, na época não.

Além disso, os filhos dos catadores passaram a participar de um projeto social chamado Recrearte, com a freqüência de 60 crianças no momento atual, além de estarem devidamente matriculados na escola, afastados assim do trabalho infantil, conforme depoimento abaixo:

As mulheres estão trabalhando aqui, e os filhos estão no Recrearte ou na escola. Temos uma parte social chamada Recrearte que são 60 crianças, filhos dos catadores cooperados e de catadores da redondeza.

Somente participam da cooperativa os catadores que tenham experiência na separação do material. Estes participam de capacitações promovidas pelo SEBRAE, que também é um 
parceiro efetivo da cooperativa, explica a entrevistada:

Aqui na cooperativa até então só entra quem é catador. Tem que conhecer o material. Não adianta a pessoa vir trabalhar na mesa se não souber separar o material. Só de papel nós temos seis qualificações (...) nós temos o SEBRAE que nos ajuda nisso.

Quanto às fontes de financiamento no processo de criação do empreendimento social, a entrevistada destaca a participação de algumas empresas públicas e privadas como a TIM MAXITEL, a MULTISERV, a CODISE e principalmente a PETROBRAS, que a partir de 2003, estabeleceu parceria com a CARE, possibilitando o crescimento dos trabalhos da cooperativa.

A entrevistada destaca que as fontes de financiamento alocadas foram e algumas continuam sendo de fundamental importância para a continuidade dos trabalhos. No entanto frisa a insuficiência de apoio financeiro do poder público municipal, que é responsável apenas pela coleta do lixo através da TORRE:

(...) a CARE é a única cooperativa no Brasil que sobrevive sem a ajuda do governo, porque nos outros lugares eles pagam pelo material que você recicla. No lugar de pagar à TORRE, pelo material que eles recolhem da rua, eles deveriam pagar à cooperativa pelo que a gente reciclou. Nos outros lugares é assim, aqui em Aracaju não é, e mesmo assim a gente consegue sobreviver.

Atualmente, a gestão da CARE se dá através de um Conselho Comercial formado pelos cooperados, a PETROBRAS, o Ministério Público, a EMSURB e todas as instituições que doam material reciclável, como o Banco do Nordeste e o Banco do Brasil.

No que concerne aos obstáculos enfrentados pela cooperativa, a entrevistada destacou que culturalmente as pessoas, de modo geral, não estão interessadas em fazer a separação do lixo produzido. Sendo assim, foi e continua sendo necessário um trabalho sócio-educativo nos bairros com o objetivo de sensibilizar a população aracajuana para a separação e correta destinação dos resíduos sólidos. Nesta direção, houve o trabalho de divulgação dos objetivos da cooperativa frente aos moradores do bairro Santa Maria e adjacências, como exemplificado nessa passagem da entrevista:

(...) tem onze anos que a gente aparece na televisão de vez em quando, vai para os bairros, faz reunião, vai para condomínios e ninguém se interessa.

Nesse contexto, o grande obstáculo que ainda não foi superado totalmente é o volume insuficiente de materiais recicláveis, em vista da capacidade produtiva da CARE, deste modo somente 45 famílias fazem parte da cooperativa, sendo que este quantitativo está aquém do que se estima que é de 150 famílias cooperadas. Além disso, alguns maquinários estão ociosos em virtude da falta de materiais, como revela a entrevistada:

Nós temos duas cortadeiras. Quando nós tínhamos uma pequenininha, faltava tempo para cortar o material. Aí a gente conseguiu num projeto uma de 1.000 $\mathrm{kg} / \mathrm{hora}$, e ela está encostada agora (...). Ela só funciona duas vezes no ano, que é em dezembro, quando o pessoal manda material dos colégios e em março que são as limpezas dos arquivos.

A carência de materiais persiste apesar de a CARE contar com a parceria efetiva da PETROBRAS no transporte dos materiais, bem como com os dois caminhões da EMSURB, que fazem a coleta seletiva no município, e com um caminhão próprio que recolhe o lixo em locais 
que fazem o pedido.

A falta de matéria-prima para o trabalho poderia ser atenuada com a participação de mais catadores, entretanto muitos destes sentem dificuldades de se adequarem aos padrões de uma cooperativa, tais como cumprimento de horários, divisão do lucro e o afastamento dos filhos do trabalho e inserção dos mesmos na escola. Também, uma orientação básica da cooperativa é a abstinência de álcool e outras drogas, o que por sua vez, gera resistência por parte dos catadores. 0 depoimento da entrevistada permite entender a situação:

(...) Fica difícil colocar na cabeça dos catadores que se eles vierem para a CARE, que eles vão ter a carroçinha deles, que eles vão trabalhar para eles mesmos, organizados, pagar o INSS deles, mas eles vão ter a responsabilidade sobre a carrocinha e vão ter que trabalhar 'de cara'. E quando eu tava na reunião dizendo a eles que eles teriam ótimos benefícios, aposentadoria, eu também falei que eles teriam de trabalhar 'de cara'. Sabe o que significa trabalhar de cara? Sem drogas, sem álcool. Daí não ficou nenhum na sala. Dos 540 que estavam na reunião não ficou nenhum.

De acordo com a entrevistada a renda produzida na cooperativa teria um aumento significativo se o número de catadores cooperados aumentasse. No entanto, mesmo com alguns projetos que visam à distribuição de carrocinhas, a dificuldade de reunir os catadores é grande, pois como dito anteriormente, estes preferem trabalhar isoladamente. Outro fato que chama a atenção é o estigma que estes catadores têm, na medida em que são chamados de "burros sem rabo", em decorrência de arrastarem os materiais coletados em equipamentos improvisados, de forma precária, resultando em problemas de saúde. Essa outra passagem do depoimento da entrevistada mostra essa dificuldade:

Ia aumentar bastante a renda se tivesse bastante material. Se esses 540 'carrinheiros' estivessem aqui, os chamados 'burros sem rabo', que são os catadores de rua com aquela carrocinha, só que como eu já disse fizemos um projeto para que eles ganhassem as carrocinhas, já que a CARE é um exemplo, mas infelizmente não deu.

No que tange aos entraves enfrentadas pela CARE, a falta de material e a falta de colaboração da sociedade comprometem o desenvolvimento de todas as atividades. No entanto, na entrevista percebeu-se claramente outra variável dificultadora que é o preço baixo da comercialização dos produtos, visto que, no estado de Sergipe, somente uma fábrica de celulose faz a compra de matéria-prima diretamente com a CARE, o que não é suficiente. A maior parte dos materiais vendidos é comercializada com os "atravessadores", isto é, os compradores que fazem o transporte para outros estados e municípios. Conseqüentemente, o lucro da venda é inferior ao que poderia ser caso a CARE tivesse condições de fazer a venda diretamente para as fábricas, como pode ser visto no depoimento:

(...) A única fábrica que tem é a indústria de celulose. 0 resto são os atravessadores. Então o que pagar mais caro eu entrego. Se pagar mais barato eu vou segurar o material até aumentar. Porque se eu for vender mais barato, no rateio eu vou ter que pagar menos.

Nesse panorama, no que concerne às perspectivas futuras da CARE, a entrevistada enfatiza a necessidade de se criar outras cooperativas de materiais recicláveis, não só em Aracaju, mas como também em outras cidades. Por conseguinte, que essas cooperativas sejam interligadas, aumentando o volume do material produzido para que assim se possa evitar a 
comercialização com os atravessadores e fazer direto com as indústrias em outras cidades.

Que cada município tenha a sua cooperativa. Que a gente fique só na base da rede, que aí a gente consegue mandar para São Paulo, Rio de Janeiro e Curitiba. Pra você ver, a gente vende o Pet aqui a $\mathrm{R} \$ 0,35$. (...) eu conseguindo mais Pet para trabalhar com aquele maquinário, que consegue fazer 10.000 $\mathrm{Kg} /$ dia, ao invés de vender a $\mathrm{R} \$ 0,35$, eu venderia a $\mathrm{R} \$ 2,30$, direto para Curitiba, e Curitiba ainda paga o frete.

Por fim, a entrevistada destaca a necessidade de maior conscientização e colaboração de todos em relação à coleta seletiva do lixo, porque é através desse trabalho que muitas famílias retiram sua renda, de forma digna. Para isso, pede maior apoio do poder público, através de um acompanhamento junto às comunidades, levando palestras de educação ambiental e trabalhando junto com as associações, com as igrejas, escolas e postos de saúde, mostrando que é preciso adquirir o hábito de selecionar o lixo orgânico do inorgânico.

\section{CONCLUSÃO}

A criação da cooperativa foi resultado de uma iniciativa do Ministério Público, UNICEF, EMSURB e UFS, que numa ação conjunta buscavam contribuir para a erradicação do alto índice de crianças que trabalhavam na lixeira, situada no bairro Santa Maria, onde residiam diversas famílias que se alojaram para trabalhar na coleta do lixo. As crianças também participavam dos trabalhos com o intuito de auxiliar seus pais na coleta do lixo estavam afastadas da escola e expostas a diversos riscos.

No período inicial da formação da CARE, as principais dificuldades enfrentadas foram o descrédito dos catadores no que concerne a proposta da cooperativa e a insuficiência de materiais recicláveis. Ao longo dos anos as dificuldades enfrentadas variam entre a carência de materiais para reciclagem e a falta de apoio efetivo da sociedade que não colabora com a coleta seletiva. Assim, é condição essencial a realização de trabalhos sócio-educativos com objetivo de sensibilizar a população para a separação e correta destinação do lixo.

A CARE conta com a parceria de empresas públicas e privadas no que tange a doação de material reciclável. No entanto, a quantidade de materiais arrecadados não é compatível com o potencial produtivo que a cooperativa possui, impossibilitando, dessa forma, o engajamento de mais famílias que sobrevivem da renda adquirida através da captação do lixo na cooperativa. Outro dado que merece destaque, é o baixo valor de comercialização da maioria dos materiais, que não são vendidos diretamente para as fábricas e indústrias, mas são interceptados por "atravessadores" que compram por um baixo custo.

No entanto é visível que a Cooperativa de Agentes Autônomos de Reciclagem de Aracaju (CARE) tem desempenhado um importante papel social para a cidade de Aracaju, na medida em que vem atuando na coleta/separação/comercialização de resíduos sólidos, com impactos positivos sobre o meio ambiente, bem como na geração de trabalho e renda para famílias vulnerabilizadas pela pobreza e exclusão social. Além disso, contribui decisivamente com a diminuição do trabalho infantil, pois os filhos dos cooperados e outros catadores estão devidamente matriculados na escola e participam de projetos sociais.

\section{BIBLIOGRAFIA}

ANDION, Carolina. As particularidades da gestão em organizações da Economia Solidária. ENCONTRO DA ASSOCIAÇÃO NACIONAL DE PÓS-GRADUAÇÃO E PESQUISA EM 
ADMINISTRAÇÃO, 25., 2001, Campinas. Anais... Campinas: ANPAD, 2001. CDROM.

CALEGARE, Marcelo Gustavo Aguilar. A transformação social no discurso de uma organização do terceiro setor. 2005. f. 193 Dissertação (Mestrado em Psicologia) Instituto de pesquisa em psicologia, Universidade de São Paulo, São Paulo.

FALCONER, Andrés Pablo. A promessa do Terceiro Setor: um estudo sobre a construção do papel das organizações sem fins lucrativos e do seu campo de gestão. 1999. Dissertação (Mestrado em Administração) - Programa de Pós-Graduação da Faculdade de Economia, Administração e Contabilidade da Universidade de São Paulo, São Paulo.

FISCHER, Rosa Maria; FALCONER, Andrés Pablo. Desafios da parceria governo e terceiro setor. Revista de Administração, São Paulo, v. 33, n. 1, p. 12-19, jan./mar., 998.

GEM. Global Entrepreneurship Monitor. Empreendedorismo no Brasil 2004: sumário executivo. Curitiba: 2005.

GIL, A. C. Métodos e técnicas de pesquisa social. São Paulo: Atlas, 1999.

GUTIERRES, Kellen Alves. Avanços e retrocessos: 0 terceiro setor e os impasses para a construção democrática no Brasil. 2006, f. 126. Dissertação (Mestrado em Ciência Política) Faculdade de Filosofia, Letras e Ciências Humanas, Departamento de Ciências Políticas, Universidade de São Paulo, São Paulo.

HOCAYEN-DA-SILVA, A. J. ; BRAGA, M. J.; DORNELAS, H. L; FARIAS, A. F. A problemática que envolve o cooperativismo de trabalho em Minas Gerais: um estudo exploratório. Revista Brasileira de Gestão e Desenvolvimento Regional. Taubaté, v. 5, n. 1, p. 3-25, jan.- abr. 2009.

IBGE. Instituto Brasileiro de Geografia e Estatística. As Entidades de Assistência Social Privadas sem Fins Lucrativos no Brasil. 2006.

LANDIM, Leilah. Para além do mercado e do Estado? Filantropia e cidadania no Brasil. Rio de Janeiro: ISER, 1993.

MEDEIROS, L. F. de R.; MACÊDO, K. B. Profissão: catador de material reciclável, entre o viver e o sobreviver. Revista Brasileira de Gestão e Desenvolvimento Regional. v. 3, n. 2, p. 72-94, maio - ago, 2007

MTE, Ministério do Trabalho e Emprego, Sistema Nacional de Informações em Economia Solidária - SIES. 2004.

OCB. Organização das Cooperativas Brasileiras. Sistema Cooperativista Brasileiro: Dados Consolidados de 2008. Mar. 2009.

ONOZATO, Erika. Processo de criação de organizações com fins sociais: Estudos de caso múltiplos no município de Curitiba. 2007, f. 177. Dissertação (Mestrado em Administração) Setor de Ciências Sociais Aplicadas, Centro de pesquisa e pós-graduação em Administração, Universidade Federal do Paraná. Curitiba.

SALAMON, Lester. A emergência do terceiro setor: uma revolução associativa global. Revista de Administração, São Paulo, v. 33, n. 1, p. 05-11, jan./mar. 1998.

SINGER, Paul. (a). Globalização e Desemprego: Diagnóstico e alternativas. 7. ed. São Paulo: 
Contexto, 2008.

SINGER, Paul. (b). Economia solidária. Estudos Avançados. São Paulo, v. 22 n. 62, p.2- 19 Jan.Apr, 2008

SINGER, Paul. Cooperativas de trabalhos. Brasília: Ministério do Trabalho e Emprego - MTE, 2004.

YIN, Robert K. Estudo de caso: planejamento e métodos. Porto Alegre: Bookman, 2001. 